\title{
Comportamento numérico da extração de óleo de girassol, simulada em extrator de leito fixo, usando propriedades características determinadas de forma experimental.
}

\author{
Gilberto Carlos Thomas Julhane Alice Thomas Schulz \\ Departamento de Matemática, Instituto Federal Farroupilha - Campus Santa Rosa \\ 98900-000, Santa Rosa, RS \\ E-mail: gthomas@sr.iffarroupilha.edu.br julhane@sr.iffarroupilha.edu.br
}

\begin{abstract}
RESUMO
A grande demanda de extração de óleos vegetais de sementes oleaginosas como girassol, soja e canola, para atender a alimentação humana e a produção de biodiesel, está em constante crescimento no Brasil e no mundo. Este processo requer o uso de métodos industriais de extração por solvente, para obtenção do óleo, esse processo deve de ter uma velocidade aceitável e eficiência econômica. Quase que na totalidade das indústrias do Brasil e do mundo, utiliza o solvente hexano neste processo.

Os extratores por solvente constituem-se de equipamentos onde a matéria-prima continuamente entra e recebe banhos de solvente, ocasionando a migração do óleo da semente para o solvente, que sai do extrator enriquecido pelo óleo. A essa mistura formada do solvente com o óleo extraído, dá-se o nome de micela, que posteriormente é processada para que o óleo seja separado.

Cada espécie de semente oleaginosa e seu cultivo têm suas particularidades e precisa de prévia preparação para ingressar no extrator, visando uma extração eficiente. Influenciam, também, no processo, a velocidade de operação do equipamento e o volume de entrada de solvente e matéria-prima no extrator.

A verificação da eficiência do processo de extração da indústria é realizada inúmeras vezes ao dia através da análise da concentração de óleo existente na micela que sai do extrator. Se o percentual de óleo na micela está abaixo do normal significa que está sendo perdido óleo retido no resíduo de matéria-prima, causando prejuízos à indústria. Tanto maior será a perda financeira quanto for a demora na constatação da ineficiência citada.

A extração de óleos vegetais, por solvente em instalações industriais de grande escala, processam até 15.000 toneladas de matéria-prima por dia de operação. O Brasil tem uma área industrial muito grande voltada à extração de óleos vegetais, como óleo de soja, canola, milho, arroz e girassol. Estas indústrias de óleo usam instalações contínuas de grande porte, com predominância de extratores de extração por solvente do tipo "Rotocell", "De Smet" e "Crow-Model". Percebe-se então à necessidade de modelos matemáticos que descrevem este processo com eficácia, de forma a poder otimizar os equipamentos e o processo de extração. Para a modelagem dos processos de extração nesses equipamentos, faz-se necessário o entendimento de extratores de complexidade menor como o extrator de "Leito-Fixo" equipamento laboratorial, pois em geral os extratores assemelham-se ao leitofixo, atuando em um sistema contra-corrente cruzado. Majumdar, et al [1] e Moreira [2] desenvolveram modelos matemáticos para um extrator leito-fixo, que levam em conta características da matéria-prima, tais como: porosidades das fases bulk e poro, constante de equilíbrio, área de contato, diâmetro da partícula.

Considerando que a bibliografia apresenta dados incompletos e divergentes relativos às matérias-primas, porém estes dados são necessários à modelagem dos equipamentos. Portanto, neste trabalho desenvolveu-se um equipamento laboratorial do tipo leito fixo, através de apoio do projeto de pesquisa Modelagem Matemática dos Processos em Extratores de Óleo Vegetal pelo Instituto Federal Farroupilha, o qual permite determinar características da matéria-prima, que não se encontram na literatura, apresenta-se neste, dados relativos a matéria-prima girassol que são praticamente inexistentes. Assim, apresenta-se aqui a determinação experimental de dados utilizados como parâmetros nos modelos matemáticos, tais como: porosidades das fases poro $\left(\varepsilon_{p}\right)$ e bulk $\left(\varepsilon_{b}\right)$; do
\end{abstract}


coeficiente de equilíbrio entre as fases poro e sólida $E_{d}$; das massas específicas do solvente $\left(\rho_{h e}\right)$, da matéria-prima $\left(\rho_{M P}\right)$ e o diâmetro da partícula $\left(d_{p}\right)$.

No modelo de leito fixo que está ligado à extração de óleo, os fenômenos considerados são: transferência do óleo contido na fase sólida para a fase poro; percolação da micela pela matéria-prima; transferência do óleo da fase poro para fase "bulk" e difusão pela coluna. As hipóteses simplificadoras implantadas no modelo matemático são as seguintes: no interior da partícula, na fase poro, a concentração de óleo é uniforme; não existe gradientes de concentrações radiais na fase "bulk"; as porosidades das partículas e do leito são constantes e uniformes; a temperatura é constante e uniforme; durante o processo de extração não há geração de calor na mistura; o solvente não penetra na fase poro; as paredes celulares da matériaprima estão totalmente rompidas.

Através do modelo matemático desenvolvido por Thomas, et al.[3], [4] e [5], que é composto por quatro equações, em derivadas ordinárias e parciais unidimensionais evolutivas, representando as variações da vazão da fase "bulk", a alteração das concentrações de óleo das fases poro e "bulk" durante a extração e a evolução da concentração média da micela no reservatório. A partir destas, foram realizadas simulações numéricas envolvendo o regime transiente e estacionário que revelam propriedades do campo de extração, podemos observar o comportamento numérico da extração de óleo de girassol, em um extrator de leito fixo. Estes resultados são comparados aos obtidos durante a extração do extrator laboratorial de leito fixo e, também, com os resultados obtidos com os do equipamento "Rotocell" de uma indústria da região Noroeste do Rio Grande do Sul.

Os resultados obtidos com a determinação experimental de dados característicos da matéria-prima girassol e a possibilidade de simulação numérica através de modelos matemáticos, estabelece parâmetros para melhor desempenho dos extratores de pequeno e grande porte. Esses dados permitirão um estudo da viabilidade econômica e otimização do processo industrial, com vistas a agregar valor à produção, transformando a safra de oleaginosa em óleo comestível ou biodiesel.

Palavras-chave: Girassol, Extrator, Modelo matemático, extração.

\section{Referências}

[1] G. C. Majumdar, et al., Modeling solvente extraction of vegetable oil in a packed bed, JAOCS, Campaing, v.t, n.9, pp.971-979, 1995.

[2] L. G. Moreira, Modelagem matemática do processo de extração de óleo vegetal por solvente em extrator de leito fixo. Ijuí. 83pp. Dissertação de Mestrado. DEFEM. Unijuí, 1998.

[3] G. C. Thomas, G. O. Veloso, V. G. Krioukov, Mathematical model of the extraction in countercurrent crossed flows. Chemical Engineering and Processing. , v.47, pp.1470 - 1477, 2008.

[4] G. C. Thomas, G. O. Veloso, V. G. Krioukov Mass transfer modelling in counter-current crossed flows in an industrial extractor. Food and Bioproducts Processing. , v.85, pp.77 - 84, 2007.

[5] G. C. Thomas, V. G. Krioukov, Simulation of vegetable oil extraction in counter-current crossed flows using the artificial neural network. Chemical Engineering and Processing. v.44, pp.581 - 592, 2005. 